\title{
Volatile Organic Compounds in the Nation's Ground Water and Drinking-Water Supply Wells-A Summary
}

Volatile organic compounds (VOCs) are produced in large volumes and are associated with a myriad of products, such as plastics, adhesives, paints, gasoline, fumigants, refrigerants, and dry-cleaning fluids. Widespread and long-term use of VOCs and their ability to persist and migrate in ground water raise questions about possible adverse effects on the environment, including drinking-water quality. A long-term investigation by the National Water-Quality Assessment (NAWQA) Program of the United States Geological Survey (USGS) provides the most comprehensive national analysis to date of the occurrence of VOCs in ground water, based on results from sampling between 1985 and 2002. Among the major findings are that VOCs were detected in most aquifers throughout the Nation, and were not limited to a few specific aquifers or regions. VOCs were not detected, however, in many of the nearly 3,500 sampled wells; for example, about 80 percent had no detections above a threshold of 0.2 part per billion. The most frequently detected VOCs were chloroform, the solvents PCE and TCE, and the gasoline oxygenate MTBE; 13 of the 55 compounds included in the assessment were not detected at all. A separate analysis of untreated groundwater samples from drinking-water supply wells showed that VOCs were detected in domestic well samples (14 percent) and public well samples (26 percent), but seldom at concentrations likely to affect human health (less than 2 percent had concentrations greater than Federal drinking-water standards). This Fact Sheet highlights selected national and regional findings on the occurrence of VOCs in ground water and in drinking-water supply wells. It serves as a companion product to a USGS Circular (1292) titled "The Quality of Our Nation's Waters - Volatile Organic Compounds in the Nation's Ground Water and Drinking-Water Supply Wells," by Zogorski and others (2006).

\section{Importance of Studying VOCs in Ground Water}

Protecting and managing ground water are critical. Nearly one-half of the Nation's population depends on ground water for drinking and other household uses, and it is an important natural resource that supports many of the Nation's industrial, agricultural, and commercial activities.

Volatile organic compounds (VOCs) are an important group of environmental contaminants to monitor and manage in ground water because of their widespread and long-term use. Many VOCs are mobile and persistent in ground water. Some are known or suspected human carcinogens and their concentrations in drinking water from public water systems are regulated by the U.S. Environmental Protection Agency (USEPA). VOCs can be released to the environment and reach ground water through many sources and pathways, including exhaust from gasoline engines, industrial air emissions, leaking storage tanks, landfills, infiltration of urban runoff and wastewater, septic systems, and injection through wells.

The National Water-Quality Assessment (NAWQA) Program investigation provides a large-scale resource characterization of VOC occurrence, and was not designed to focus on local VOC contamination of ground water, such as at landfills and leaking underground storage tanks (see sidebar 1). The assessment was also not designed to relate specific sources to VOC detections in wells. Findings do, however, provide preliminary insights on several human and natural factors associated with the occurrence of VOCs in ground water, including aquifer characteristics, the physical and chemical characteristics of the compounds, and land-use activities.

\section{VOC Study Design}

National findings on the occurrence of 55 VOCs in ambient, untreated ground water are based on data collected or compiled as part of 98 aquifer studies within the NAWQA Program during 1985-2002 from about 3,500 wells that were selected randomly and distributed across broad areas. The aquifer studies were located throughout the conterminous United States as well as in Alaska and Hawaii. The NAWQA analysis was based on one sample per well. The resulting assessment provides an aquifer-scale resource characterization of the occurrence of VOCs. Findings can be used to make decisions regarding water-resource protection and water-supply management at regional and national levels.

A separate analysis, limited to wells used only for drinking-water supply (domestic and public), was conducted to specifically address possible drinking-water issues of concern by water utilities, public health agencies, and citizens. Samples were collected at the wellhead before any treatment or blending, and thus the analyses do not necessarily indicate the chemical composition of water ingested by consumers using domestic or public wells. Domestic wells are defined in this assessment as privately owned, self-supplied sources for drinking water and other household uses. Public wells are privately or publicly owned and supply ground water for public water systems. This analysis of source waters included data from 2,401 domestic wells and 1,096 public wells. It is important to note that about 2,500 of the wells included in this analysis of source waters met the objectives of, and were therefore also part of, the aquifer-resource assessment described above. The remaining wells used in the analysis of source waters (about 1,000 ) were sampled by scientists associated with other USGS Programs or other agencies (all of which met approved USGS and USEPA quality-assured methodology). More information on the approach, planning, and design of this assessment can be found at http://water.usgs.gov/nawqa/vocs/national_assessment/ 


\section{VOC Occurrence}

VOCs were detected in most aquifers throughout the Nation, and were not limited to a few specific aquifers or regions. VOCs were not detected, however, above a threshold of 0.2 part per billion in 80 percent of the sampled wells.

VOCs were detected in most aquifers across the Nation. Specifically, at least one of the 55 VOCs was detected in at least one well sample in 90 of the 98 aquifer studies assessed by the NAWQA Program from 1985 to 2002. Despite their nationwide occurrence, no VOCs were detected in samples from about 80 percent of the nearly 3,500 wells included in the 98 aquifer studies. Detection frequencies cited throughout this document are based on a threshold level of 0.2 part per billion (or microgram per liter). For perspective, detection levels for public drinking-water compliance monitoring for regulated VOCs are set by Federal regulations at 0.5 part per billion.

In general, detections of most VOCs - primarily solvents, gasoline hydrocarbons, trihalomethanes (THMs), and refrigerants-were relatively evenly distributed across the Nation. Exceptions included gasoline oxygenates, such as methyl tert-butyl ether (MTBE), which were detected primarily in aquifers in the New England and Mid-Atlantic States; and agricultural fumigants, such as ethylene dibromide (EDB) and dibromochloropropane (DBCP), which were detected predominantly in aquifers in the Central Valley of California and in Oahu, Hawaii. The occurrence of gasoline oxygenates and fumigants is, in large part, related to regional patterns of their use.

Most (three-fourths) of the 55 VOCs were detected at least once in the aquiferstudy assessment; however, about 15 compounds accounted for most detections (see table 1). The most frequently detected VOC - in about 7 percent of the samples-was the THM chloroform. Chloroform and other THMs are disinfection by-products from the chlorination of water. The solvents perchloroethene (PCE) and trichloroethene (TCE), the gasoline oxygenate MTBE, and the gasoline hydrocarbon toluene also were among the top five most frequently detected compounds. Thirteen of the 55 VOCs were not detected in any samples.

Mixtures of multiple VOCs were detected in some water samples. The

Table 1. A total of $24 \mathrm{VOCs}$ are listed below because they were either (1) among the most frequently detected VOCs in aquifer studies (defined as detected in greater than 1 percent of samples), or (2) detected in at least one domestic or public well sample, collected prior to treatment or blending, at a concentration greater than or within a factor of 10 of a Maximum Contaminant Level (MCL). Such detections may warrant their inclusion in future studies or monitoring of ground water.

[X, Yes; - , No; NA, Not applicable because these VOCs do not have MCLs]

\begin{tabular}{|c|c|c|c|}
\hline Volatile organic compound & $\begin{array}{l}\text { Detected in at } \\
\text { least } 1 \text { percent } \\
\text { of samples } \\
\text { from aquifer } \\
\text { studies }\end{array}$ & $\begin{array}{l}\text { Detected in sam- } \\
\text { ples from drinking- } \\
\text { water supply wells } \\
\text { at a concentration } \\
\text { greater than an } \\
\text { MCL }\end{array}$ & $\begin{array}{l}\text { Detected in samples } \\
\text { from drinking-water } \\
\text { supply wells at a } \\
\text { concentration less } \\
\text { than, but within a } \\
\text { factor of } 10 \text { of an } \\
\text { MCL }\end{array}$ \\
\hline \multicolumn{4}{|c|}{ Fumigants } \\
\hline Dibromochloropropane (DBCP) & - & $\mathrm{X}$ & $\mathrm{X}$ \\
\hline 1,2-Dichloropropane & - & $\mathrm{X}$ & $\mathrm{X}$ \\
\hline Ethylene dibromide (EDB) & - & $\mathrm{X}$ & - \\
\hline \multicolumn{4}{|c|}{ Gasoline hydrocarbons } \\
\hline Benzene & - & - & $\mathrm{X}$ \\
\hline Toluene & $\mathrm{X}$ & - & - \\
\hline \multicolumn{4}{|c|}{ Gasoline oxygenate } \\
\hline Methyl tert-butyl ether (MTBE) & $\mathrm{X}$ & NA & NA \\
\hline \multicolumn{4}{|c|}{ Organic synthesis compounds } \\
\hline 1,1-Dichloroethene (1,1-DCE) & - & $\mathrm{X}$ & $\mathrm{X}$ \\
\hline Vinyl chloride & - & $\mathrm{X}$ & $\mathrm{X}$ \\
\hline \multicolumn{4}{|c|}{ Refrigerants } \\
\hline $\begin{array}{l}\text { Dichlorodifluoromethane (CFC- } \\
\text { 12) }\end{array}$ & $\mathrm{X}$ & NA & NA \\
\hline Trichlorofluoromethane (CFC-11) & $\mathrm{X}$ & NA & NA \\
\hline \multicolumn{4}{|c|}{ Solvents } \\
\hline Carbon tetrachloride & - & - & $\mathrm{X}$ \\
\hline Chloromethane & $\mathrm{X}$ & NA & NA \\
\hline 1,1-Dichloroethane (1,1-DCA) & $\mathrm{X}$ & NA & NA \\
\hline 1,2-Dichloroethane (1,2-DCA) & - & - & $\mathrm{X}$ \\
\hline $\begin{array}{l}\text { cis-1,2-Dichlorethene (cis-1,2- } \\
\text { DCE) }\end{array}$ & - & - & $\mathrm{X}$ \\
\hline $\begin{array}{l}\text { trans-1,2-Dichloroethene (trans- } \\
\text { 1,2-DCE) }\end{array}$ & $\mathrm{X}$ & - & - \\
\hline Methylene chloride & $\mathrm{X}$ & $\mathrm{X}$ & $\mathrm{X}$ \\
\hline Perchloroethene (PCE) & $\mathrm{X}$ & $\mathrm{X}$ & $\mathrm{X}$ \\
\hline Trichloroethene (TCE) & $\mathrm{X}$ & $\mathrm{X}$ & $\mathrm{X}$ \\
\hline 1,1,1-Trichloroethane (TCA) & $\mathrm{X}$ & - & $\mathrm{X}$ \\
\hline \multicolumn{4}{|c|}{ Trihalomethanes } \\
\hline Chloroform & $\mathrm{X}$ & - & $\mathrm{X}$ \\
\hline Bromodichloromethane & $\mathrm{X}$ & - & $\mathrm{X}$ \\
\hline Bromoform & $\mathrm{X}$ & - & $\mathrm{X}$ \\
\hline Dibromochloromethane & $\mathrm{X}$ & - & $\mathrm{X}$ \\
\hline
\end{tabular}

most common mixtures of compounds (at a concentration greater than 0.2 part per billion) included PCE, TCE, and chloroform. Specific mixtures of these compounds were detected in less than 2 percent of the wells. Mixtures can result from multiple compounds sharing the same source and from the widespread occurrence of VOCs in ground water.
Mixtures also can result from degradation of a parent compound to other compounds. For example, although TCE is produced and used as a solvent, its occurrence in ground water can be enhanced as the parent compound (PCE) biodegrades to TCE under certain environmental conditions. NAWQA data on the occurrence of VOC mixtures can help to identify 
those that are most commonly detected in the Nation's ground water and in drinking-water supply wells.

"Detections" of VOCs summarized in this document are at low concentrations ( 0.2 part per billion) and do not necessarily indicate adverse effects in ground water or potential human-health concern if the water is ingested. In fact, concentrations of individual VOCs in most samples were below Federal drinking-water standards or other humanhealth benchmarks (see next section), and the total (or summed) concentration of all VOCs in samples typically were less than 1 part per billion. The NAWQA Program uses analytical methods designed to measure concentrations of contaminants at low levels in order to comprehensively assess VOC occurrence in the Nation's ambient ground water, to identify emerging issues related to the presence of VOCs in ground water, to track changes in concentrations over time, and to gain insights about natural and anthropogenic factors that explain VOC detections. The national occurrence of VOCs has not been documented previously because most monitoring, such as that for compliance with drinking-water standards, does not focus on aquifer-scale resource assessments or measure concentrations at comparable low levels.

\section{Potential for Effects on Human Health}

VOCs were detected in samples from drinking-water supply wells, but seldom at concentrations likely to affect human health.

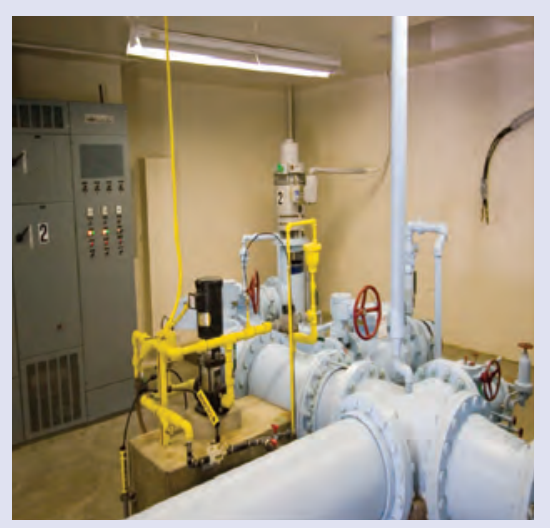

VOC concentrations in this assessment were greater than MCLs in about 2 percent of public well samples. VOCs were detected more frequently in public well samples (26 percent) than in domestic well samples (14 percent). This is most likely attributed to the location of public wells in developed, more urbanized areas where VOC sources and releases are more common than in rural areas. Higher detection frequencies also may relate to greater withdrawal rates of public wells compared to domestic wells, which can increase the movement of contaminated ground water to public wells. This finding is consistent with results of a companion USGS study that showed many VOCs - such as solvents, gasoline hydrocarbons, and refrigerants - were detected more frequently and at greater concentrations in ground water that served as a drinkingwater supply for very large community water systems (serving more than 50,000 people) than in ground water serving as a supply for smaller systems (Grady, 2003).
The U.S. Geological Survey (USGS) conducted a separate analysis of VOCs detected only in drinking-water supply wells to understand what VOC concentrations may mean to human health. Specifically, concentrations of VOCs in samples collected from domestic and public wells prior to any treatment or blending were standards (USEPA Maximum Contaminant Levels, or MCLs) and to USGS Health-Based Screening Levels (HBSLs), another human-health benchmark (see sidebar 2).

samples from 2,401 domestic wells and in 26 percent of samples from 1,096 public wells. VOC concentrations typically were below human-health benchmarks. Specifically, concentrations were greater

\section{Human-Health Benchmarks Used in this Assessment}

When volatile organic compounds (VOCs) are detected in untreated samples from drinking-water supply wells, it is important to understand what these results may mean to human a screening- feve step toward understanding VOC occurrence in the context of human health, health benchmarks. The screening-level assessment is intended to identify VOC concentrations that may be of potential concern and to prioritize needs for further investigation; it is not a substitute for comprehensive risk assessment, such as done by the U.S. Environmental Protection Agency (USEPA). Concentrations of VOCs in samples from drinking-water supply wells were compared to USEPA Maximum Contaminant Levels (MCLs) for 27 of the 44 VOCs detected in this assessment. USGS worked with USEPA, New Jersey Department of Environ-

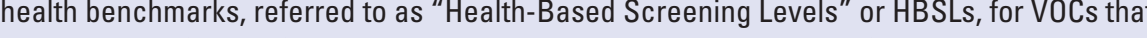
toxicity information. HBSLs were calculated for 8 of the 17 unregulated VOCs that were detected in this assessment, but were not calculated for the remaining unregulated VOCs because of a lack of toxicity information. Additional information about HBSLs and ongoing

than the USEPA MCLs in only about 1 percent of samples from domestic wells (or 29 wells), and in about 2 percent of samples from public wells (or 16 wells). Concentrations greater than MCLs were represented, in large part, by the agricultural fumigant DBCP (in domestic wells only) and the solvents PCE and TCE (see

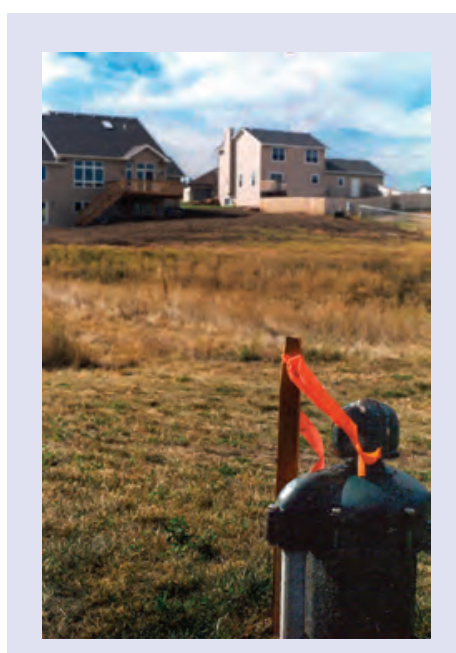

Most concentrations of VOCs in domestic well samples were below human-health benchmarks and about 1 percent of the samples had concentrations greater than Federal drinking-water standards (MCLs). Trihalomethanes (THMs), solvents, refrigerants, and gasoline oxygenates were the most commonly occurring groups of VOCs. Monitoring the quality of water from domestic wells is primarily the well owner's responsibility, however, most States and some local agencies provide guidance to domestic well owners through Web sites and printed material. 
table 1). No samples contained concentrations greater than HBSLs.

The USGS study evaluated drinking-water supplies prior to any treatment or blending. This initial screening-level assessment helps to evaluate what VOC concentrations captured in domestic- and public-well water may mean to human health. Results can be used to identify and prioritize specific compounds to consider in long-term monitoring and in other future studies (see table 1). Table 1 also lists VOCs detected at concentrations less than, but within a factor of 10 of human-health benchmarks. Nine VOCs were detected at concentrations less than, but within a factor of 10 of an MCL; no sample contained concentrations of VOCs that were less than, but within a factor of 10 of an HBSL.

It is important to note some complexities in the evaluation of VOCs within a human-health context (Toccalino and others, 2006). For example, the presence of VOCs in drinking water at concentrations greater than human-health benchmarks, such as MCLs or HBSLs, does not necessarily indicate that adverse human-health effects will occur, even if the water is ingested; toxicity-based models used to develop MCLs and HBSLs assume lifetime exposure, whereas actual exposure may be less than a lifetime. In addition, water-treatment processes can lower VOC concentrations below human-health benchmarks. Additional information on what VOC concentrations may mean in a human-health context is provided elsewhere (Toccalino and others, 2006).

\section{Relations to Sources, Transport, and Fate}

Each VOC has a unique pattern of occurrence depending on its sources, patterns of use, and factors that control its transport and fate in ground water.

Many small-scale studies have been conducted to investigate VOC sources and the large number of chemical and physical properties that control their transport and fate in the environment. These studies indicate that the occurrence of VOCs in ground water depends on multiple factors, including, but not limited to the following:

- Geographic and temporal extent of production and use of VOCs in industry, commerce, and household products;
- Types and locations of VOC sources relative to sampled wells;

- Extent of urban land use in the vicinity of the well;

- Chemical and physical characteristics of the compounds themselves, such as their mobility and persistence;

- Aquifer characteristics, including the presence or absence of dissolved oxygen, hydrogeology, and water-table depth;

- Pumping stress on the aquifer;

- Soil characteristics and climate;

- Timing and amount of recharge to the ground-water system; and

- Timing of VOC releases to the environment and the age of ground water.

Although this NAWQA assessment was not designed to examine specific sources, transport processes, and chemical and physical factors to VOC concentrations in samples from individual wells, general patterns and associations emerged from national-scale analyses of VOCs commonly detected in aquifer studies. Two patterns relate to human activities and are associated with urban land use and production, and two relate to natural features and are associated with levels of dissolved oxygen in the ground water and lithology.

- Urban Land Use and Sources-The occurrence of VOCs commonly corresponded to percentage of urban land use within a one-half kilometer radius of sampled wells (see sidebar 3). VOC occurrence also was commonly associated with the presence of Resource Conservation and Recovery Act (RCRA) hazardous waste facilities, underground gasoline storage tanks, and septic systems.

- Production-Estimated production rates of VOCs did not correspond directly to VOC detection frequencies, which can be explained in part because production rates may not reflect when, where, and which VOCs actually are released to the environment. In addition, production data for some VOCs were sparse and could only be estimated.

- Dissolved Oxygen-Detections of VOCs differed with dissolved-oxygen conditions in ground water, in large part because rates of biodegradation of VOCs vary under different dissolved-oxygen conditions. In general, the detection frequencies for VOCs in the NAWQA assessment are consistent with published biodegradation rates associated with dissolved oxygen. Some VOCs, such as chloroform and PCE, were detected more frequently in oxygenated ground water than in nonoxygenated ground water. In contrast, methylene chloride and chloromethane were detected more frequently in nonoxygenated ground water.

- Lithology - The frequency of VOC detections varied widely in aquifers, regardless of lithology, which is the physical characteristics of the rock comprising an aquifer (such as sandstone, carbonate, crystalline, basalts, and sand and gravel).

\section{Occurrence of Selected VOCs}

The occurrence of individual VOCs in ground water is governed by patterns of use, chemical and physical properties,

\section{VOCs and Urban Land Use}

VOC detections generally were higher in shallow ground water underlying urban areas than in shallow ground water underlying other land-use areas. Specifically, 38 percent of shallow wells sampled by NAWOA in residential and commercial areas contained at least one VOC. In contrast, about 11 percent of shallow wells in agricultural areas contained at least one VOC. Urban areas have more sources and releases of VOCs compared to agricultural areas because VOCs are used extensively in industrial, commercial, and household activities. In addition, recharge of VOCs to ground water may be enhanced in urban areas by manmade structures, such as recharge basins and shallow injection wells. It is worth noting that local variations in VOCs in ground water do occur. For example, VOC contamination in Hawaii is greater in unconfined ground water underlying agricultural areas in central $0 \mathrm{ahu}$, where fumigants have been intensively applied, than in shallow ground water underlying urban Honolulu. Attention to potential VOC contamination in shallow ground water is warranted because this water can move downward into deeper aquifers used for drinking-water supply. Because ground-water movement is usually slow, contamination may take many years to disperse. 
and the characteristics of the hydrologic system. The role of these factors is illustrated by highlighting findings for selected VOCs, most of which were commonly detected in the NAWQA assessment. For each compound, findings are presented from the (1) broad-scale resource characterization of 98 aquifers, and (2) separate analysis of drinkingwater supply wells.

\section{Chloroform and Other THMs}

Chloroform, a trihalomethane, was the most frequently detected VOC in aquifers and in drinking-water supply wells.

Chloroform was the most frequently detected VOC in ground water-in about 7 percent of samples collected in the 98 aquifer studies. Chloroform has many industrial uses, including the production of refrigerants for home air conditioners and large commercial freezers, and it also has been used in reagents, extraction solvents, fumigants, insecticides, and as a precursor for dyes and pesticides. Chloroform and other THMs are commonly produced during the chlorination of drinking waters and wastewaters, and in the disinfection of domestic and public wells (Ivahnenko and Zogorski, 2006). These compounds also may be present in the effluent of domestic septic systems from the use of bleach and other household cleaning products that contain chlorine.

The extensive and relatively long period of use of chlorine has allowed ample time for recharge of waters containing chloroform to reach many of the sampled aquifers. Chloroform persists in aquifers with relatively high concentrations of dissolved oxygen and has a relatively low tendency to attach to soil and aquifer material. Chloroform can thereby move substantial distances with ground water and remain in the aquifer system for many years.

Chloroform was the most frequently detected VOC in samples from domestic and public wells - in 5 and 11 percent of domestic and public wells, respectively. Concentrations of chloroform and the three other THMs (bromodichloromethane, dibromochloromethane, and bromoform) were relatively low in domestic and public wells; concentrations were below the USEPA drinking-water standard (MCL) of 80 parts per billion, which is established for the summed concentration of all four compounds. Prolonged exposure to THMs is associated with chronic human-health concerns, including cancer and damage to the liver, kidneys, and central nervous system.

Artificial recharge of water containing chloroform and other THMs to aquifers that are used as drinkingwater supplies is becoming more common, especially in western States. The relatively high detection frequencies of chloroform in samples from domestic and public wells indicates that continued routine monitoring of these chemicals is needed over the long term, especially in areas where artificial recharge of chlorinated waters is commonly practiced.

\section{MTBE}

MTBE was among the most frequently detected VOCs in samples from many aquifers and drinking-water supply wells, despite its relatively recent history of use.

MTBE was the third most frequently detected VOC in samples from aquifer studies - in about 3 percent of samples collected in the 98 aquifer studies. The distribution of MTBE detections was not uniform among aquifers across the Nation. The greatest detection frequency of MTBE was in areas: (1) with high population density, (2) where MTBE was used as an oxygenate in reformulated gasoline, and (3) with high rates of ground-water recharge, such as in the highly populated New England and MidAtlantic States.

MTBE is an oxygenate added to gasoline to improve combustion and to reduce harmful vehicle emissions. From the mid-1990s, the production of MTBE increased dramatically as the use of oxygen-containing compounds in gasoline was required in areas of the Nation where certain air-quality standards were not attained. In 2005, the U.S. Congress passed the Energy Policy Act that eliminated the oxygen requirement in gasoline by mid-2006. Removal of the oxygen requirement is expected to decrease the use of MTBE in gasoline in the future.

Because of its physical properties, MTBE has been frequently detected in ground water despite its relatively short use history. These properties, including high solubility in water and low sorption to organic matter in soil and aquifer material, allow MTBE to reach ground water and to travel faster and farther than many other common gasoline components. In addition, the biodegradation of MTBE in ground water is relatively slow; MTBE can therefore persist longer in aquifer systems relative to many other gasoline compounds, such as benzene and toluene.

MTBE was detected in 3 and 5 percent of domestic and public wells, respectively. Concentrations were typically less than the lower limit of the USEPA drinking-water consumer advisory concentration range of 20-40 parts per billion, which is based on taste and odor thresholds. In fact, only one drinkingwater sample, which was from a domestic well, had a concentration of MTBE equal to the lower limit of the drinking-water consumer advisory. No Federal drinkingwater standard (MCL) exists for MTBE at this time. A USEPA quantitative risk assessment is in process; studies indicate that MTBE may affect the kidneys and liver and may have carcinogenic effects.

MTBE has been used intensively in gasoline for only about 10 years. Because of the complex nature of ground-water flow, and the high solubility and mobility of MTBE, the future distribution patterns of MTBE are unknown. Continued routine monitoring of MTBE is needed, especially in areas of high use of MTBE in gasoline, such as in the New England and Mid-Atlantic States (see sidebar 4).

\section{PCE and TCE}

PCE and TCE were among the VOCs that most frequently had concentrations in drinking-water supply wells greater than Federal drinking-water standards.

The chlorinated solvents PCE and TCE were the second and fourth most frequently detected VOCs in samples from the 98 aquifer studies-detected in about 4 and 3 percent of samples, respectively. Chlorinated solvents are organic compounds containing chlorine and are used in a variety of industrial, commercial, and domestic applications. For example, PCE is used as a solvent by more than 80 percent of commercial dry cleaners. Although TCE is commonly used as a solvent, it also can be formed from the biodegradation of its parent compound, PCE, especially in non-oxygenated ground-water conditions. Although large quantities of these solvents are still used today, their production began declining as early as the 1970s. 
Chlorinated solvents have physical properties that allow them to be transported to, and be persistent in, ground water. In general, these solvents have relatively high densities, which allow them to penetrate the water table, and a high solubility, which allows them to move readily with ground water. The half-lives of solvents in ground water generally are longer than those of other commonly used VOCs, like gasoline hydrocarbons. This means that solvents can persist for relatively long periods of time in certain aquifers.

PCE and TCE were detected in 2 and 1 percent of samples from domestic wells, respectively, and in 5 percent and 4 percent of samples from public wells, respectively. These two solvents accounted for a large majority of concentrations greater than Federal drinkingwater standards. Specifically, PCE and TCE ranked first among VOCs with concentrations greater than MCLs in samples collected from public wells, and second and third for domestic wells. Chlorinated solvents have been associated with cancer and other human-health concerns. The USEPA is expecting final reassessments of health effects of PCE, TCE, and other solvents during 2006-2008.

Widespread and long-term use, mobility and persistence in ground water, and a relatively large number of concentrations greater than the MCLs for PCE and TCE indicate that continued monitoring of these chlorinated solvents in ground water is warranted. In addition, because the production of both PCE and TCE has been declining over the past several decades, monitoring over the long-term will help to track any changes in their concentrations in ambient ground water and drinking-water supply wells.

\section{DBCP and Other Fumigants}

Most detections of fumigants were limited to areas of intensive fumigant use.

Detections of fumigants in samples generally were limited to areas of known and intense fumigant use, such as in California and Hawaii. Specifically, fumigants were detected in 30 percent of samples from aquifers underlying Oahu, Hawaii, and in 10 percent of samples from aquifers underlying the Central Valley of California. These detection frequencies compare to an overall national detection frequency of fumigants in the 98 aquifer studies of about 2 percent.

\section{MTBE was Detected in Drinking Water in New England and Mid-Atlantic States}

MTBE was detected in drinking water collected from community water systems in 10 New England and Mid-Atlantic States in a study conducted by the USGS in cooperation with the USEPA Office of Ground Water and Drinking Water (Grady and Casey, 2001). MTBE was detected in about 9 percent of the water systems. Consistent with other assessments, concentrations were low; less than 1 percent of the samples had concentrations of MTBE greater than the USEPA drinking-water advisory concentration of 20-40 parts per billion. Most concentrations (82 percent of detections) in drinking water were less than 5 parts per billion, which has been established as an aesthetic standard by some States.

Fumigants in ground water in the Central Valley of California are believed to be associated with the historical application of DBCP to vineyards and almond orchards. The fumigant detections on Oahu have resulted, in large part, from fumigant applications containing EDB, 1,2-dichloropropane, and 1,2,3-trichloropropane to pineapple fields. In 1970, for example, about 1.8 million pounds of fumigants were applied to pineapple fields on Oahu to combat rootworms.

Fumigant formulations containing DBCP, EDB, 1,2-dichloropropane, and 1,2,3-trichloropropane were banned in the United States during the late 1970s to early 1980s after about 20 to 30 years of use. Fumigants continue to persist in ground water underlying Oahu, areas of California, and elsewhere because of their prior extensive use combined with slow biodegradation of the compounds.

Fumigants accounted for about twothirds of concentrations larger than drinking-water standards (MCLs) in samples from domestic wells. About one-half of these concentrations were accounted for by the fumigant DBCP, which was used from the late 1950s to the late 1970s. Most of the elevated concentrations were in samples collected in California.

\section{References}

Grady, S.J., 2003, A national survey of methyl tert-butyl ether and other volatile organic compounds in drink- ing-water sources-Results of the Random Survey: U.S. Geological Survey Water-Resources Investigations Report 02-4079, 85 p.

Grady, S.J. and Casey, G.D., 2001, Occurrence and distribution of methyl tert-butyl ether and other volatile organic compounds in drinking water in the Northeast and Mid-Atlantic regions of the United States, 199398: U.S. Geological Survey WaterResources Investigations Report 00-4228, 123 p.

Ivahnenko, Tamara, and Zogorski, J.S., 2006, Sources and occurrence of chloroform and other trihalomethanes in drinking-water supply wells in the United States, 1986-2001: U.S. Geological Survey Scientific Investigations Report 2006-5015, 13 p.

Toccalino, P.L., Rowe, B.L., and Norman, J.E., 2006, Volatile organic compounds in the Nation's drinking-water supply wells-What findings may mean to human health: U.S. Geological Survey Fact Sheet 2006-3043, 4 p.

Zogorski, J.S., and others, 2006, The Quality of Our Nation's Water-Volatile organic compounds in the Nation's ground water and drinking-water supply wells. U.S. Geological Survey Circular 1292, $101 \mathrm{p}$.

By Michael J. Moran, Pixie A. Hamilton, and John S. Zogorski

\section{USGS Promotes Public Access to Water-Quality Information}

This Fact Sheet and VOC Circular are free of charge and are on the World Wide Web at http://water.usgs.gov/nawqa/ vocs/national_assessment. Included at this Web site are downloadable maps on VOC occurrence, information on sampling designs and methodology, background on data analyses, and frequently asked questions.

\section{Contact for additional information or questions}

John S. Zogorski, Project Chief, VOC National Synthesis

U.S. Geological Survey

1608 Mountain View Road

Rapid City, SD 57702

Email: jszogors@usgs.gov

(605) 394-3214 